\title{
A Novel Closed-Form Solution for Circular Openings in Generalized Hoek-Brown Media
}

\author{
Qing Xiang Meng ${ }^{1,2}$ and Wei Wang ${ }^{1,2}$ \\ ${ }^{1}$ Institute of Geotechnical Engineering, Hohai University, Nanjing 210098, China \\ ${ }^{2}$ Key Laboratory of Ministry of Education for Geomechanics and Embankment Engineering, Hohai University, Nanjing 210098, China
}

Correspondence should be addressed to Wei Wang; wwang@hhu.edu.cn

Received 4 April 2014; Accepted 21 August 2014; Published 25 September 2014

Academic Editor: Shueei M. Lin

Copyright ( 2014 Q. X. Meng and W. Wang. This is an open access article distributed under the Creative Commons Attribution License, which permits unrestricted use, distribution, and reproduction in any medium, provided the original work is properly cited.

\begin{abstract}
A novel closed-form solution is presented in this paper for the estimation of displacements around circular openings in a brittle rock mass subject to a hydrostatic stress field. The rock mass is assumed to be elastic-brittle-plastic media governed by the generalized Hoek-Brown yield criterion. The present closed-form solution was validated by employing the existing analytical solutions. Results of several example cases are analyzed to show that, with the simplified assumption, a novel closed-form solution is derived and found to be in an excellent agreement with those obtained by using the exact integration method with mathematical software. Parametric sensitivity analysis is carried out and the parameter $a_{r}$ tends to be the sensitive factor. As a closed-form solution that does not require transformation technique and the use of any numerical method, this work can provide a better choice in the preliminary design for circular opening.
\end{abstract}

\section{Introduction}

Analysis for the stress and displacement around a circular opening is a common problem widely used in geotechnical, petroleum, and mining engineering. For this reason, a large number of analyses of circular tunnel in an infinite medium subjected to a hydrostatic in situ stress have been presented by considering different models of material behavior, such as the ideal plastic, brittle plastic, strain-softening models, with the different yield criteria like the linear Mohr-Coulomb yield criterion and the nonlinear Hoek-Brown criteria. Detailed reviews of such works can be seen in [1-11]. Although there are numerical solutions for stresses and displacements such as FEM, but a closed-form solution is still preferred in a preliminary design.

The Hoek-Brown failure criterion is an empirical criterion based on triaxial behavior of rock mass, large scale tests, and experience [12]. Over the past several decades, the HoekBrown criterion has been widely used in rock engineering, especially for a jointed rock mass where the Mohr-Coulomb failure criterion is not valid. Meanwhile, the Hoek-Brown failure criterion has changed several times and is found to be suitable ranged from hard rock masses to poor qualities of rock masses now [13].

The latest generalized Hoek-Brown yield criterion can be expressed in the following form [14]:

$$
\sigma_{1}=\sigma_{3}+\sigma_{c}\left(m \frac{\sigma_{3}}{\sigma_{c}}+s\right)^{a},
$$

where $\sigma_{1}$ and $\sigma_{3}$ are the major and minor principal stresses, respectively; $\sigma_{c}$ is the uniaxial compressive strength of the intact rock; $m$ is a reduced value of the material constant $m_{i}$ and is given by

$$
m=m_{i}\left(\frac{\mathrm{GSI}-100}{28-14 D}\right),
$$

where $s$ and $a$ are constants for the rock mass given by the following relationships:

$$
\begin{gathered}
s=\exp \left(\frac{\mathrm{GSI}-100}{9-3 D}\right), \\
a=\frac{1}{2}+\frac{1}{6}\left(e^{-\mathrm{GSI} / 15}-e^{-20 / 3}\right) .
\end{gathered}
$$


In the equations above, $m_{i}$ is a material constant for the intact rock, GSI is the Geological Strength Index of the rock mass, and $D$ is a rock mass disturbance factor. The ranges of GSI and $D$ are normally as follows: $10 \leq$ GSI $\leq 100$ and $0 \leq D \leq 1$. The value of GSI $=100$ represents an extremely poor quality of rock mass, and $D=1$ corresponds to a highly disturbed rock mass. For GSI $=100$, the value of the constant $a$ is equal to 0.5 . In this case, the generalized failure criterion can degenerate to the original Hoek-Brown failure criterion.

For the axial symmetry of the problem, the radial and tangential stress are the principle stresses; namely, $\sigma_{1}=\sigma_{\theta}$ and $\sigma_{3}=\sigma_{r}$. The criterion for the rock mass can be expressed as follows:

$$
\begin{gathered}
\sigma_{\theta}=\sigma_{r}+\sigma_{c}\left(m \frac{\sigma_{r}}{\sigma_{c}}+s\right)^{a} \text { for peak strength, } \\
\sigma_{\theta}=\sigma_{r}+\sigma_{c r}\left(m_{r} \frac{\sigma_{r}}{\sigma_{c r}}+s_{r}\right)^{a_{r}} \text { for postpeak strength, }
\end{gathered}
$$

where $\sigma_{c r}, m_{r}, s_{r}$, and $a_{r}$ are the residual values of HoekBrown constants for the yielded rock.

For a circular opening in generalized Hoek-Brown media, Canrranza-Torres [2] developed analytical solutions for displacements and stresses based on a transformation technique. The solution is a second-ordered differential equation requiring the use of numerical methods. Sharan [7] obtained exact and closed-form solutions without using any transformation. Closed-form solutions proposed by Sharan [7] were derived approximately by considering the plastic zone as the thickwalled cylinder. However, it has a relatively high error in large displacements.

Based on the elastic stress-strain relationship, this note proposed a closed-form solution for the prediction of displacement around a circular opening in an elastic-brittleplastic rock mass compatible with a nonlinear Hoek-Brown yield criterion and a nonassociate flow rule. Comparing the closed-form solutions presented by Sharan [7], the results of this work were found to have a better performance.

\section{Analysis of Stresses and Displacements}

2.1. Analytical Solutions for Stresses. A circular opening in a homogeneous infinite isotropic Hoek-Brown rock mass subjected to a hydrostatic in situ stress $\sigma_{0}$ was employed in this paper. The internal pressure $p_{0}$ acts on the surface of the tunnel uniformly (Figure 1). It is known that the rock mass was in elastic state before excavation. The internal pressure is gradually decreased after excavation and the plastic zone will appear when the elastic limit is reached. For the brittle behavior of rock mass, the strength of rock drops suddenly and obeys the postyield softening criterion.

The differential equation of equilibrium for the axisymmetric problem can be written as

$$
\sigma_{\theta}=\sigma_{r}+r \frac{d \sigma_{r}}{d r}
$$

In plastic zone, the stresses are governed by (5). The stresses in the plastic zone can be derived by substituting (5)

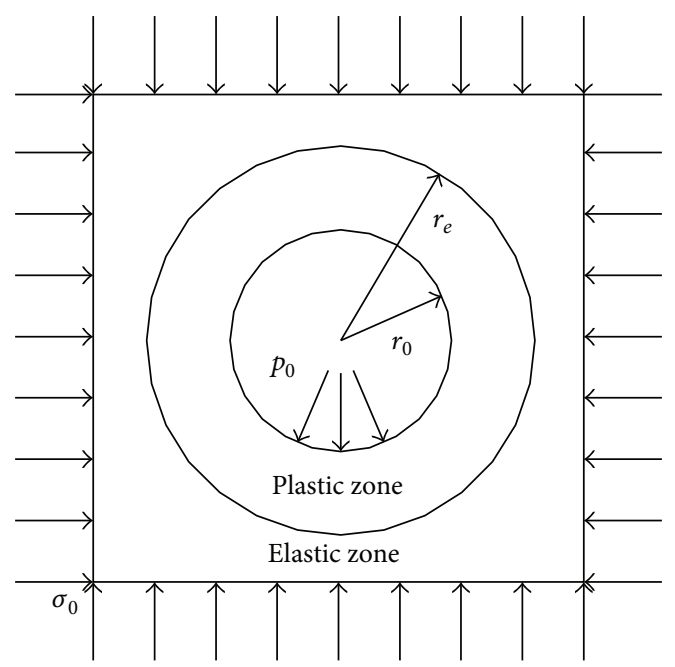

FIgURE 1: A circular tunnel subject to hydrostatic initial stress field.

into (6) with the consideration of the boundary condition $\sigma_{r}=p_{0}$ at $r=r_{0}$ :

$$
\begin{gathered}
\sigma_{r}=\left[k_{1}+k_{2} \ln \left(\frac{r}{r_{0}}\right)\right]^{k_{3}}+k_{4}, \\
\sigma_{\theta}=\left[k_{1}+k_{2} \ln \left(\frac{r}{r_{0}}\right)\right]^{k_{3}}+k_{2} k_{3}\left[k_{1}+k_{2} \ln \left(\frac{r}{r_{0}}\right)\right]^{k_{3}-1}+k_{4},
\end{gathered}
$$

where

$$
\begin{aligned}
& k_{1}=\left(p_{0}+\frac{\sigma_{c r} s_{r}}{m_{r}}\right)^{1-a_{r}}, \\
& k_{2}=\left(1-a_{r}\right) m_{r}\left(\frac{m_{r}}{\sigma_{c r}}\right)^{a_{r}-1}, \\
& k_{3}=\frac{1}{1-a_{r}}, \\
& k_{4}=-\frac{s_{r} \sigma_{c r}}{m_{r}} .
\end{aligned}
$$

The radial stress $\sigma_{r}$ at the interface of elastic and plastic zone can be expressed as follows $[6,15]$ :

$$
\sigma_{R}=\sigma_{R 0}+\frac{2\left(\sigma_{0}-\sigma_{R 0}\right)-\sigma_{c} C^{a}}{2+a m C^{a-1}},
$$

where

$$
\begin{gathered}
C=m \frac{\sigma_{R 0}}{\sigma_{c}}+s \\
\sigma_{R 0}=\sigma_{0}+\frac{1}{8}\left[m \sigma_{c}-\sqrt{\sigma_{c}\left(m^{2} \sigma_{c}+16 \sigma_{0} m+16 s \sigma_{c}\right)}\right] .
\end{gathered}
$$

Thus, the radial of plastic zone $R$ can be obtained by substituting (10) into (7).

$$
R=r_{0} \exp \left[\frac{\left(\sigma_{R}-k_{4}\right)^{1 / k_{3}}-k_{1}}{k_{2}}\right] .
$$


The radial and tangential stresses in the elastic zone can be derived easily by solving the following equations:

$$
\begin{aligned}
& \sigma_{r}=\sigma_{0}-\left(\sigma_{0}-\sigma_{R}\right)\left(\frac{R}{r}\right)^{2}, \\
& \sigma_{\theta}=\sigma_{0}+\left(\sigma_{0}-\sigma_{R}\right)\left(\frac{R}{r}\right)^{2} .
\end{aligned}
$$

2.2. Analytical Solutions for Displacements. As for the solutions for the displacement, there are three cases. The first case is the assumption of the constant elastic strain in the plastic region, the second case is considering the plastic region as the thick-walled cylinder subjected to the inner stress and the outer stress, and the third one is using the stress-strain relationship strictly. The first two techniques are approximate methods. The last method is accurate but it cannot be solved in a closed-form solution. In most cases, the third case is chosen in the calculation of the deformation of the opening [9-11]. Here, we propose a novel closed-form solution with high accuracy based on the stress-strain relationship.

In the plastic region, radial and tangential strains, $\varepsilon_{r}$ and $\varepsilon_{\theta}$, can be divided into elastic and plastic parts:

$$
\begin{aligned}
& \varepsilon_{r}=\varepsilon_{r}^{e}+\varepsilon_{r}^{p}, \\
& \varepsilon_{\theta}=\varepsilon_{\theta}^{e}+\varepsilon_{\theta}^{p} .
\end{aligned}
$$

The strains can be expressed in terms of inward radial displacement $u$ as follows:

$$
\begin{aligned}
\varepsilon_{r} & =\frac{d u}{d r} \\
\varepsilon_{\theta} & =\frac{u}{r} .
\end{aligned}
$$

By using the small deformation theory and a nonassociate flow rule, the plastic parts of radial and tangential strains for the plane strain condition have the relationship as

$$
\varepsilon_{r}^{p}+K_{d} \varepsilon_{\theta}=0
$$

By combining (13) and (16), the function of radial displacement can be written as

$$
\frac{d u}{d r}+K_{d} \frac{u}{r}=f(r)
$$

where $f(r)=\varepsilon_{r}^{e}+K_{d} \varepsilon_{\theta}^{e}$.

The boundary condition for the radial displacement at the interface of elastic and plastic zone can be expressed as

$$
u_{R}=\frac{1+v}{E} R\left(\sigma_{0}-\sigma_{R}\right) .
$$

With the consideration of the continuity of radial displacement, the differential equation can be expressed as follows:

$$
u=r^{-K_{d}} \int_{R}^{r} r^{k_{d}} f(r) d r+u_{R}\left(\frac{R}{r}\right)^{K_{d}} .
$$

By using the elastic stress-strain relationship, the elastic strains can be written as follows with the consideration of initial hydrostatic stress:

$$
\begin{aligned}
& \varepsilon_{r}^{e}=\frac{1+v}{E_{r}}\left[(1-v)\left(\sigma_{r}-\sigma_{0}\right)-v\left(\sigma_{\theta}-\sigma_{0}\right)\right], \\
& \varepsilon_{\theta}^{e}=\frac{1+v}{E_{r}}\left[(1-v)\left(\sigma_{\theta}-\sigma_{0}\right)-v\left(\sigma_{r}-\sigma_{0}\right)\right] .
\end{aligned}
$$

By substituting (7)-(8) into (22), the expression of $f(r)$ can be written as

$$
\begin{aligned}
f(r)= & k_{5}\left[k_{1}+k_{2} \operatorname{In}\left(\frac{r}{r_{0}}\right)\right]^{k_{3}} \\
& +k_{6}\left[k_{1}+k_{2} \operatorname{In}\left(\frac{r}{r_{0}}\right)\right]^{k_{3}-1}+k_{7},
\end{aligned}
$$

where

$$
\begin{aligned}
& k_{5}=\frac{1+v}{E_{r}}(1-2 v)\left(1+k_{d}\right), \\
& k_{6}=\frac{1+v}{E_{r}}\left(K_{d}-v K_{d}-v\right) k_{2} k_{3}, \\
& k_{7}=-\frac{1+v}{E_{r}}(1-2 v)\left(1+K_{d}\right)\left(\sigma_{0}-k_{4}\right) .
\end{aligned}
$$

After the acquisition of $f(r)$, it can be easily found that the equation cannot be solved analytically. As for the generalized Hoek-Brown criterion, the constant $a$ is found to be nearly 0.5 , and the value of $k_{3}$ is around 2 . Hence, an approximation $\left[k_{1}+k_{2} \ln \left(r / r_{0}\right)\right]^{k_{3}-2}=1$ can be assumed and the displacement of the circular opening can be solved approximately in a closed-form based on the mathematical analysis [16]:

$$
\begin{aligned}
u= & k_{8} r\left[k_{1}+k_{2} \operatorname{In}\left(\frac{r}{r_{0}}\right)\right]^{k_{3}}+k_{9} r\left[k_{1}+k_{2} \operatorname{In}\left(\frac{r}{r_{0}}\right)\right]^{k_{3}-1} \\
& +k_{10} r+u_{A}\left(\frac{R}{r}\right)^{K_{d}},
\end{aligned}
$$

where

$$
\begin{aligned}
& k_{8}= \frac{k_{5}}{k_{d}+1}, \\
& k_{9}=-\frac{k_{2} k_{3} k_{5}}{\left(k_{d}+1\right)^{2}}+\frac{k_{6}}{k_{d}+1}, \\
& k_{10}= \frac{k_{2}^{3} k_{3} k_{5}\left(k_{3}-1\right)}{\left(k_{d}+1\right)^{3}}-\frac{k_{2} k_{6}\left(k_{3}-1\right)}{\left(k_{d}+1\right)^{2}}+\frac{k_{7}}{k_{d}+1}, \\
& u_{A}= u_{R}-k_{8} R\left[k_{1}+k_{2} \operatorname{In}\left(\frac{R}{r_{0}}\right)\right]^{k_{3}} \\
& \quad-k_{9} R\left[k_{1}+k_{2} \operatorname{In}\left(\frac{R}{r_{0}}\right)\right]^{k_{3}-1}+k_{10} R .
\end{aligned}
$$


TABLE 1: Basic properties of rock mass used for numerical tests.

\begin{tabular}{|c|c|c|c|c|c|}
\hline Rock example & A & $\mathrm{B}$ & $\mathrm{C}$ & $\mathrm{D}$ & E \\
\hline Quality of rock mass & Very good & Average & Very poor & Very poor & Very poor \\
\hline$\sigma_{c}(\mathrm{MPa})$ & 150 & 80 & 20 & 30 & 5 \\
\hline$\sigma_{c r}(\mathrm{MPa})$ & 150 & 80 & 20 & 25 & 5 \\
\hline$E(\mathrm{GPa})$ & 42 & 9 & 1.4 & 5.7 & 0.224 \\
\hline$E_{r}(\mathrm{GPa})$ & 10 & 5 & 1.4 & 5.7 & 0.224 \\
\hline$v$ & 0.2 & 0.25 & 0.3 & 0.3 & 0.3 \\
\hline$a$ & 0.5 & 0.51 & 0.52 & 0.55 & 0.585 \\
\hline$m$ & 10.2 & 2.01 & 0.657 & 1.7 & 0.402 \\
\hline$s$ & 0.062 & 0.0039 & 0.0004 & 0.0039 & $4.54 E-05$ \\
\hline$a_{r}$ & 0.51 & 0.53 & 0.52 & 0.6 & 0.585 \\
\hline$m_{r}$ & 1.27 & 0.34 & 0.657 & 0.85 & 0.402 \\
\hline$s_{r}$ & 0.0002 & 0 & 0.0004 & 0.0019 & $4.54 E-05$ \\
\hline$K_{d^{\text {est }}}$ & 1.5 & 1.15 & 1 & 1 & 1 \\
\hline$K_{d^{\max }}$ & 4.3 & 2.02 & 1.51 & 1.98 & 1.39 \\
\hline
\end{tabular}

TABLE 2: Comparison of results for a very good quality rock mass (Example A).

\begin{tabular}{|c|c|c|c|c|c|c|c|c|}
\hline \multirow{2}{*}{ Plastic behaviour } & \multirow{2}{*}{$\sigma_{0}(\mathrm{MPa})$} & \multirow{2}{*}{$p_{0}(\mathrm{MPa})$} & \multirow{2}{*}{$K_{d}$} & \multicolumn{3}{|c|}{$u_{0} / r_{0}(\%)$} & \multicolumn{2}{|c|}{ Error (\%) } \\
\hline & & & & Exact & Sharan [7] & This work & Sharan [7] & This work \\
\hline \multirow{9}{*}{ Perfectly plastic } & 37.5 & 0 & 1.0 & 0.11 & 0.11 & 0.11 & 0.0 & 0.0 \\
\hline & 37.5 & 0 & 1.5 & 0.11 & 0.11 & 0.11 & 0.0 & 0.0 \\
\hline & 37.5 & 0 & 4.3 & 0.12 & 0.12 & 0.12 & 0.2 & 0.0 \\
\hline & 75 & 0 & 1.0 & 0.25 & 0.25 & 0.25 & 0.0 & 0.0 \\
\hline & 75 & 0 & 1.5 & 0.26 & 0.26 & 0.26 & 0.2 & 0.0 \\
\hline & 75 & 0 & 4.3 & 0.32 & 0.33 & 0.32 & 2.4 & 0.0 \\
\hline & 150 & 0 & 1.0 & 0.62 & 0.62 & 0.62 & 0.0 & 0.0 \\
\hline & 150 & 0 & 1.5 & 0.68 & 0.69 & 0.68 & 0.8 & 0.0 \\
\hline & 150 & 0 & 4.3 & 1.15 & 1.26 & 1.15 & 10 & 0.0 \\
\hline \multirow{11}{*}{ Brittle plastic } & 37.5 & 0 & 1.0 & 0.27 & 0.27 & 0.27 & 0.0 & 0.0 \\
\hline & 37.5 & 0 & 1.5 & 0.31 & 0.31 & 0.31 & 0.4 & 0.0 \\
\hline & 37.5 & 0 & 4.3 & 0.66 & 0.68 & 0.66 & 3.9 & 0.0 \\
\hline & 75 & 0 & 1.0 & 1.09 & 1.09 & 1.09 & 0.0 & 0.0 \\
\hline & 75 & 0 & 1.5 & 1.40 & 1.42 & 1.40 & 1.7 & 0.0 \\
\hline & 75 & 0 & 4.3 & 5.01 & 5.69 & 4.98 & 13.7 & -0.6 \\
\hline & 150 & 0 & 1.0 & 5.30 & 5.30 & 5.30 & 0.0 & 0.0 \\
\hline & 150 & 0 & 1.5 & 7.94 & 8.26 & 7.91 & 4.1 & -0.4 \\
\hline & 150 & 2 & 1.5 & 4.49 & 4.62 & 4.47 & 2.8 & -0.4 \\
\hline & 150 & 0 & 4.3 & $7.09 E+01$ & $9.22 E+01$ & 70.3 & 30 & -0.8 \\
\hline & 150 & 12 & 4.3 & 4.28 & 4.64 & 4.25 & 8.4 & -0.7 \\
\hline
\end{tabular}

Besides, the radial displacement $u_{0}$ at the opening surface can be derived by substituting $r=r_{0}$ into (25):

$$
u_{0}=k_{8} r_{0} k_{1}^{k_{3}}+k_{9} r_{0} k_{1}^{k_{3}-1}+k_{10} r_{0}+u_{A}\left(\frac{R}{r}\right)^{k_{d}} \text {. }
$$

\section{Validation and Sensitivity Analysis}

3.1. Validation. In order to validate the accuracy of this novel closed-form solution, the results of this work and that of Sharan [7] based on the second assumption are listed. Five different examples of rock masses referenced from his paper were employed in this study. Examples A and B correspond to very good and average qualities of rock masses, respectively. Examples C-E correspond to very poor quality of rock mass.
The related parameters of generalized Hoek-Brown criterion were the same as in [7]. Basic properties of rock mass used for numerical tests are listed in Table 1. From the derivation of the closed-form solutions, it can be seen that the stresses and the radius of the elastic-plastic interface of the two studies are the same. Thus, this paper concentrated on the discussion of radial displacements. The results calculated by Sharan [7] and our newly closed-form solution were shown in Tables 2, 3 , and 4 .

For all the cases analyzed, the results calculated by the closed-form solution proposed in this note were more close to the exact solutions than those by Sharan [7]. For a nondilating rock mass, both the solutions proposed in this note and by Sharan [7] for displacements $u_{0}$ are identical 
TABLE 3: Comparison of results for an average good quality rock mass (Example B).

\begin{tabular}{|c|c|c|c|c|c|c|c|c|}
\hline \multirow{2}{*}{ Plastic behaviour } & \multirow{2}{*}{$\sigma_{0}(\mathrm{MPa})$} & \multirow{2}{*}{$p_{0}(\mathrm{MPa})$} & \multirow{2}{*}{$K_{d}$} & \multicolumn{3}{|c|}{$u_{0} / r_{0}(\%)$} & \multicolumn{2}{|c|}{ Error $(\%)$} \\
\hline & & & & Exact & Sharan [7] & This work & Sharan [7] & This work \\
\hline \multirow{11}{*}{ Perfectly plastic } & 20 & 0 & 1.00 & 0.44 & 0.44 & 0.44 & 0.0 & 0.0 \\
\hline & 20 & 0 & 1.15 & 0.45 & 0.45 & 0.45 & 0.3 & 0.0 \\
\hline & 20 & 0 & 2.02 & 0.55 & 0.57 & 0.55 & 2.9 & 0.0 \\
\hline & 40 & 0 & 1.00 & 1.34 & 1.34 & 1.34 & 0.0 & 0.0 \\
\hline & 40 & 0 & 1.15 & 1.43 & 1.44 & 1.42 & 0.9 & -0.7 \\
\hline & 40 & 0 & 2.02 & 2.08 & 2.24 & 2.06 & 7.9 & -1.0 \\
\hline & 80 & 0 & 1.00 & 5.05 & 5.05 & 5.05 & 0.0 & 0.0 \\
\hline & 80 & 0 & 1.15 & 5.64 & 5.76 & 5.63 & 2.0 & -0.2 \\
\hline & 80 & 1 & 1.15 & 4.32 & 4.39 & 4.31 & 1.7 & -0.2 \\
\hline & 80 & 0 & 2.02 & 10.8 & 12.6 & 10.7 & 16.7 & -0.9 \\
\hline & 80 & 5 & 2.02 & 4.03 & 4.41 & 4 & 9.4 & -0.7 \\
\hline \multirow{16}{*}{ Brittle plastic } & 20 & 0 & 1.00 & 2.96 & 2.96 & 2.96 & 0.0 & 0.0 \\
\hline & 20 & 0 & 1.15 & 3.44 & 3.48 & 3.43 & 1.2 & -0.3 \\
\hline & 20 & 0 & 2.02 & 8.08 & 8.77 & 8.05 & 8.6 & -0.4 \\
\hline & 20 & 1 & 2.02 & 1.73 & 1.79 & 1.72 & 3.5 & -0.6 \\
\hline & 40 & 0 & 1.00 & 20.3 & 20.3 & 20.3 & 0.0 & 0.0 \\
\hline & 40 & 3 & 1.00 & 3.7 & 3.7 & 3.7 & 0.0 & 0.0 \\
\hline & 40 & 0 & 1.15 & 25.8 & 26.3 & 25.7 & 2.2 & -0.4 \\
\hline & 40 & 3 & 1.15 & 4.19 & 4.24 & 4.19 & 1.0 & 0.0 \\
\hline & 40 & 0 & 2.02 & $1.04 E+02$ & $1.19 E+02$ & $1.03 E+02$ & 14.2 & -0.8 \\
\hline & 40 & 5 & 2.02 & 4.34 & 4.56 & 4.32 & 5.0 & -0.5 \\
\hline & 80 & 0 & 1.00 & $2.42 E+02$ & $2.42 E+02$ & $2.42 E+02$ & 0.0 & 0.0 \\
\hline & 80 & 18 & 1.00 & 4.99 & 4.99 & 4.99 & 0.0 & 0.0 \\
\hline & 80 & 0 & 1.15 & $3.52 E+02$ & $3.63 E+02$ & $3.52 E+02$ & 3.0 & 0.0 \\
\hline & 80 & 20 & 1.15 & 4.44 & 4.48 & 4.44 & 0.7 & 0.0 \\
\hline & 80 & 0 & 2.02 & $3.25 E+03$ & $3.85 E+03$ & $3.23 E+03$ & 18.6 & -0.6 \\
\hline & 80 & 24 & 2.02 & 4.49 & 4.65 & 4.47 & 3.4 & -0.4 \\
\hline
\end{tabular}

to the exact solutions. But for large displacements, even in unstable opening or excessively large displacement, our new solutions can have a high accuracy. The maximum error in displacement $u_{0}$ was $16.7 \%$ without the consideration of excessively large displacement, while it is $2.3 \%$ considering all cases. Despite the uncertainties of rock mass properties, a higher accuracy is still needed in engineering. From the results of all the cases in Tables 2-4, the closed-form solutions in this paper can be employed as a better simple method in preliminary design with a high accuracy.

3.2. Sensitivity Analysis. The sensitivity of each parameter on the overall result is discussed by using a control variable method. We take the parameters of a very good rock mass with a dilation parameter $K_{d}=1.2$ as the reference. A rangeability of $20 \%$ for each parameter with the in situ stress of $75 \mathrm{MPa}$ and support pressure of zero is applied in the sensitivity analysis. By using the method proposed in this paper when the support pressure is zero, we compute the sensitivity of the different parameters and the results are shown in Figures 2 and 3.

As for conventional mechanical parameters, the deformations are sensitive to the residual uniaxial compressive strength parameter $\sigma_{c r}$. For the Hoek-Brown parameters, the residual variable $a_{r}$ has a great influence on the overall result. Therefore more attentions should be paid to the estimation of residual variable $a_{r}$ in the preliminary analysis.

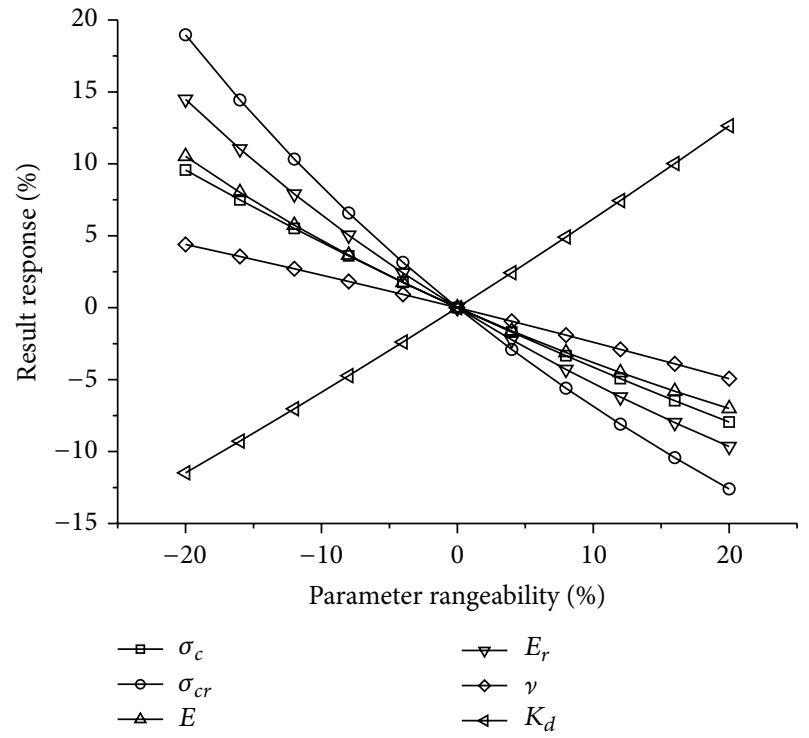

FIgURE 2: The sensitivity of conventional mechanical parameters.

\section{Conclusions}

A novel closed-form solution for a circular opening in rock mass governed by generalized Hoek-Brown failure criterion is proposed in this paper. Unlike the existing solutions 
TABLE 4: Comparison of results for very poor quality rock mass (Examples C-E).

\begin{tabular}{|c|c|c|c|c|c|c|c|c|}
\hline \multirow{2}{*}{ Rock example } & \multirow{2}{*}{$\sigma_{0}(\mathrm{MPa})$} & \multirow{2}{*}{$p_{0}(\mathrm{MPa})$} & \multirow{2}{*}{$K_{d}$} & \multicolumn{3}{|c|}{$u_{0} / r_{0}(\%)$} & \multicolumn{2}{|c|}{ Error (\%) } \\
\hline & & & & Exact & Sharan [7] & This work & Sharan [7] & This work \\
\hline \multirow{10}{*}{$\mathrm{C}$} & 5 & 0 & 1 & 1.72 & 1.72 & 1.72 & 0.0 & 0.0 \\
\hline & 5 & 0 & 1.51 & 2.41 & 2.56 & 2.41 & 6.4 & 0.0 \\
\hline & 10 & 0 & 1 & 7.89 & 7.89 & 7.89 & 0.0 & 0.0 \\
\hline & 10 & 1 & 1 & 2.44 & 2.44 & 2.44 & 0.0 & 0.0 \\
\hline & 10 & 0 & 1.51 & 13.7 & 15.3 & 13.7 & 11.6 & 0.0 \\
\hline & 10 & 1 & 1.51 & 3.28 & 3.47 & 3.27 & 5.9 & -0.3 \\
\hline & 20 & 0 & 1 & $5.27 E+01$ & $5.27 E+01$ & $5.27 E+01$ & 0.0 & 0.0 \\
\hline & 20 & 4 & 1 & 5.04 & 5.04 & 5.04 & 0.0 & 0.0 \\
\hline & 20 & 0 & 1.51 & $1.28 E+02$ & $1.49 E+02$ & $1.27 E+02$ & 17 & -0.7 \\
\hline & 20 & 5 & 1.51 & 4.95 & 5.24 & 4.93 & 5.8 & -0.4 \\
\hline \multirow{10}{*}{$\mathrm{D}$} & 8 & 0 & 1 & 0.94 & 0.94 & 0.94 & -0.1 & 0.0 \\
\hline & 8 & 0 & 1.98 & 2.08 & 2.22 & 2.07 & 6.7 & -0.5 \\
\hline & 15 & 0 & 1 & 4.06 & 4.05 & 4.05 & 0.0 & 0.0 \\
\hline & 15 & 3 & 1 & 0.52 & 0.52 & 0.52 & 0.0 & 0.0 \\
\hline & 15 & 0 & 1.98 & 13.6 & 15.2 & 13.4 & 11.8 & -1.5 \\
\hline & 15 & 1 & 1.98 & 2.65 & 2.82 & 2.61 & 6.5 & -1.5 \\
\hline & 30 & 0 & 1 & $2.80 E+01$ & $2.80 E+01$ & $2.80 E+01$ & 0.0 & 0.0 \\
\hline & 30 & 3 & 1 & 3.92 & 3.92 & 3.92 & 0.0 & 0.0 \\
\hline & 30 & 0 & 1.98 & $1.75 E+02$ & $2.06 E+02$ & $1.72 E+02$ & 17.2 & -1.6 \\
\hline & 30 & 5 & 1.98 & 4.51 & 4.83 & 4.43 & 7.1 & -1.8 \\
\hline \multirow{12}{*}{ E } & 1 & 0 & 1 & 7.91 & 7.91 & 7.91 & 0.0 & 0.0 \\
\hline & 1 & 0.1 & 1 & 1.73 & 1.73 & 1.73 & 0.0 & 0.0 \\
\hline & 1 & 0 & 1.39 & $1.30 E+01$ & $1.40 E+01$ & $1.33 E+01$ & 9.8 & 2.3 \\
\hline & 1 & 0.1 & 1.39 & 2.22 & 2.32 & 2.24 & 4.8 & 0.9 \\
\hline & 3 & 0 & 1 & $1.86 E+02$ & $1.86 E+02$ & $1.86 E+02$ & 0.0 & 0.0 \\
\hline & 3 & 0.5 & 1 & 8.98 & 8.98 & 8.98 & 0.0 & 0.0 \\
\hline & 3 & 0 & 1.39 & $4.78 E+02$ & $5.47 E+02$ & $4.77 E+02$ & 14.5 & -0.2 \\
\hline & 3 & 0.6 & 1.39 & 9.7 & 10.42 & 9.7 & 7.5 & 0.0 \\
\hline & 5 & 0 & 1 & $1.23 E+03$ & $1.23 E+03$ & $1.23 E+03$ & 0.0 & 0.0 \\
\hline & 5 & 2 & 1 & 4.72 & 4.72 & 4.72 & 0.0 & 0.0 \\
\hline & 5 & 0 & 1.39 & $4.24 E+03$ & $4.91 E+03$ & $4.22 E+03$ & 15.8 & -0.4 \\
\hline & 5 & 2.2 & 1.39 & 4.39 & 4.54 & 4.37 & 3.5 & -0.5 \\
\hline
\end{tabular}

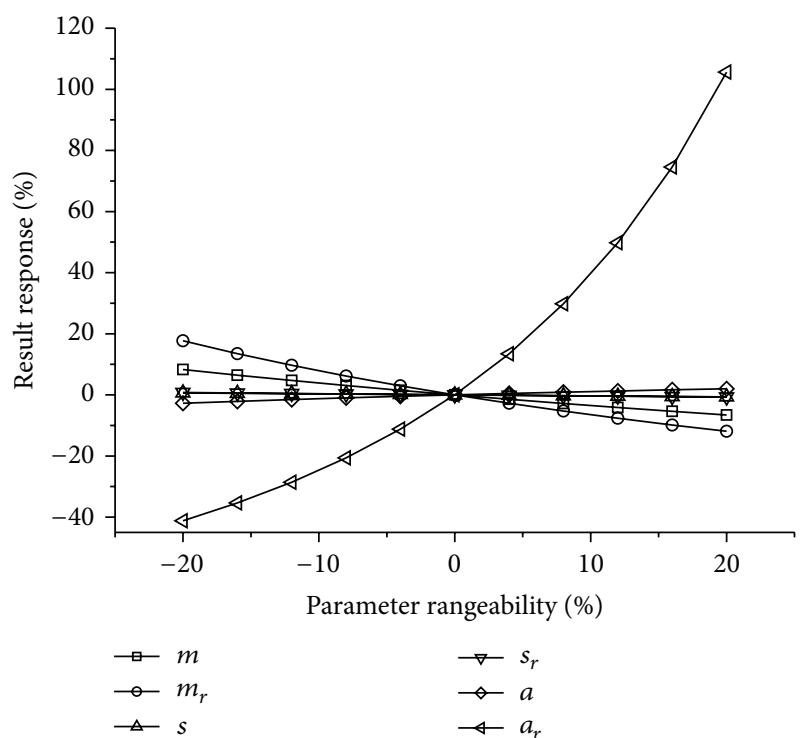

FIgURE 3: The sensitivity of Hoek-Brown parameters. for the displacement in the plastic zone which are derived approximately by considering the plastic zone as the thickwalled cylinder, the solution presented in this paper is based on the exact elastic stress-strain relationship without any transformations. By analyzing several practical cases, results show that the closed-form solution proposed in this note has a higher accuracy than Sharan [7] with a maximum error of $2.3 \%$ for all cases. Therefore, the work proposed in this paper can be employed as a simple method in preliminary design for circular opening.

\section{Conflict of Interests}

The authors declare that there is no conflict of interests regarding the publication of this paper.

\section{Acknowledgments}

The authors would like to acknowledge Dr. Shueei M. Lin for the valuable suggestions. Besides, this study is supported 
by the National Natural Science Foundation of China (Grant no. 51109069) and the Fundamental Research Funds for the Central Universities (no. 2014B04914).

\section{References}

[1] E. T. Brown, J. W. Bray, B. Ladanyi, and E. Hoek, "Ground response curves for rock tunnels," Journal of Geotechnical Engineering, vol. 109, no. 1, pp. 15-39, 1983.

[2] C. Carranza-Torres, "Elasto-plastic solution of tunnel problems using the generalized form of the Hoek-Brown failure criterion," International Journal of Rock Mechanics and Mining Sciences, vol. 41, supplement 1, pp. 629-639, 2004.

[3] Z. Guan, Y. Jiang, and Y. Tanabasi, "Ground reaction analyses in conventional tunnelling excavation," Tunnelling and Underground Space Technology, vol. 22, no. 2, pp. 230-237, 2007.

[4] K.-H. Park and Y.-J. Kim, "Analytical solution for a circular opening in an elastic-brittle-plastic rock," International Journal of Rock Mechanics and Mining Sciences, vol. 43, no. 4, pp. 616$622,2006$.

[5] S. K. Sharan, "Elastic-brittle-plastic analysis of circular openings in Hoek-Brown media," International Journal of Rock Mechanics and Mining Sciences, vol. 40, no. 6, pp. 817-824, 2003.

[6] S. K. Sharan, "Exact and approximate solutions for displacements around circular openings in elastic-brittle-plastic HoekBrown rock," International Journal of Rock Mechanics and Mining Sciences, vol. 42, no. 4, pp. 542-549, 2005.

[7] S. K. Sharan, "Analytical solutions for stresses and displacements around a circular opening in a generalized Hoek-Brown rock," International Journal of Rock Mechanics and Mining Sciences, vol. 45, no. 1, pp. 78-85, 2008.

[8] Y. Wang, "Ground response of circular tunnel in poorly consolidated rock," Journal of Geotechnical Engineering, vol. 122, pp. 703-708, 1996.

[9] A. Z. Lu, G. S. Xu, F. Sun, and W. Q. Sun, "Elasto-plastic analysis of a circular tunnel including the effect of the axial in situ stress," International Journal of Rock Mechanics and Mining Sciences, vol. 47, no. 1, pp. 50-59, 2010.

[10] A.-Z. Lu, L.-Q. Zhang, and N. Zhang, "Analytic stress solutions for a circular pressure tunnel at pressure and great depth including support delay," International Journal of Rock Mechanics and Mining Sciences, vol. 48, no. 3, pp. 514-519, 2011.

[11] S. Wang, Z. Wu, M. Guo, and X. Ge, "Theoretical solutions of a circular tunnel with the influence of axial in situ stress in elastic-brittle-plastic rock," Tunnelling and Underground Space Technology, vol. 30, pp. 155-168, 2012.

[12] E. Hoek and E. T. Brown, "Practical estimates of rock mass strength," International Journal of Rock Mechanics and Mining Sciences, vol. 34, no. 8, pp. 1165-1186, 1997.

[13] E. Hoek and P. Marinos, "A brief history of the development of the Hoek-Brown failure criterion," Soils and Rocks, vol. 30, no. 2, pp. 85-92, 2007.

[14] E. Hoek, C. Carranza-Torres, and B. Corkum, "Hoek-Brown failure criterion-2002 edition," in Proceedings of NARMS-TAC, pp. 267-273, 2002.

[15] A. I. Sofianos, "Tunnelling Mohr-Coulomb strength parameters for rock masses satisfying the generalized Hoek-Brown criterion," International Journal of Rock Mechanics and Mining Sciences, vol. 40, no. 3, pp. 435-440, 2003.

[16] C. Canuto and A. Tabacco, Mathematical Analysis I, Springer, New York, NY, USA, 2009. 


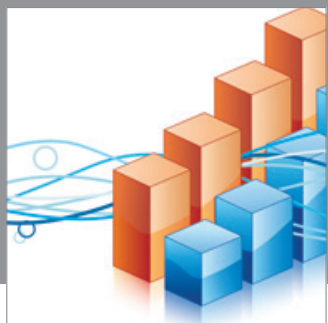

Advances in

Operations Research

mansans

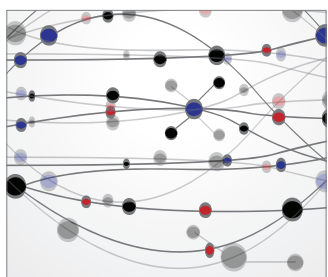

The Scientific World Journal
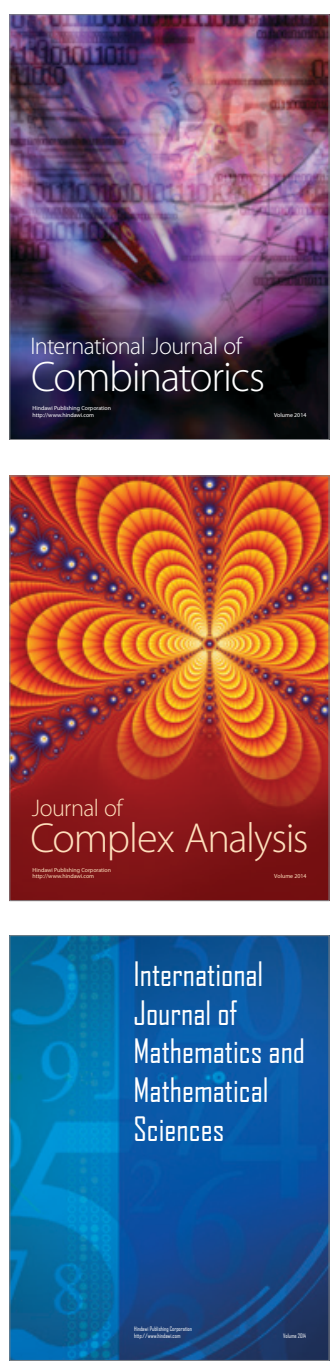
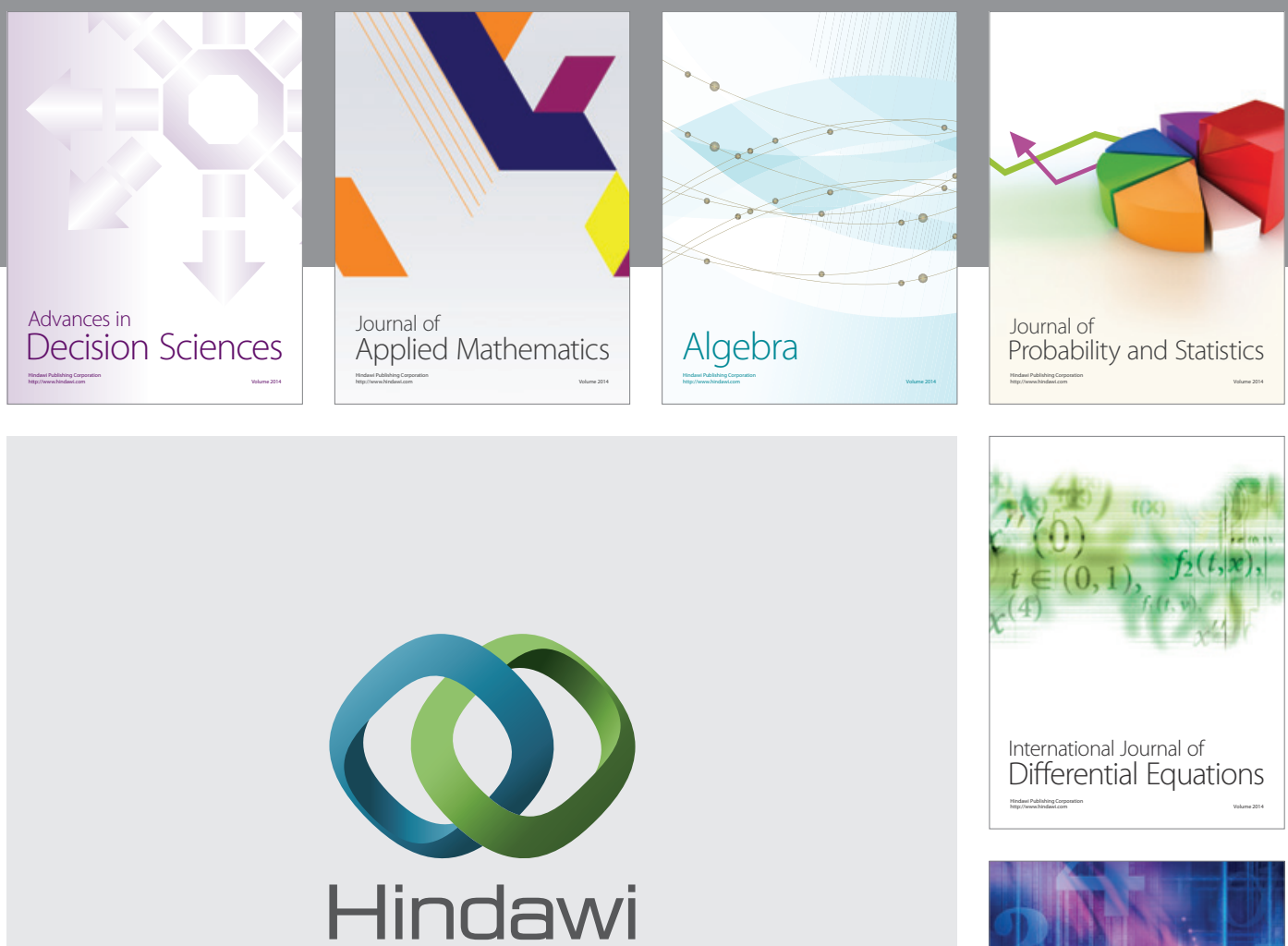

Submit your manuscripts at http://www.hindawi.com
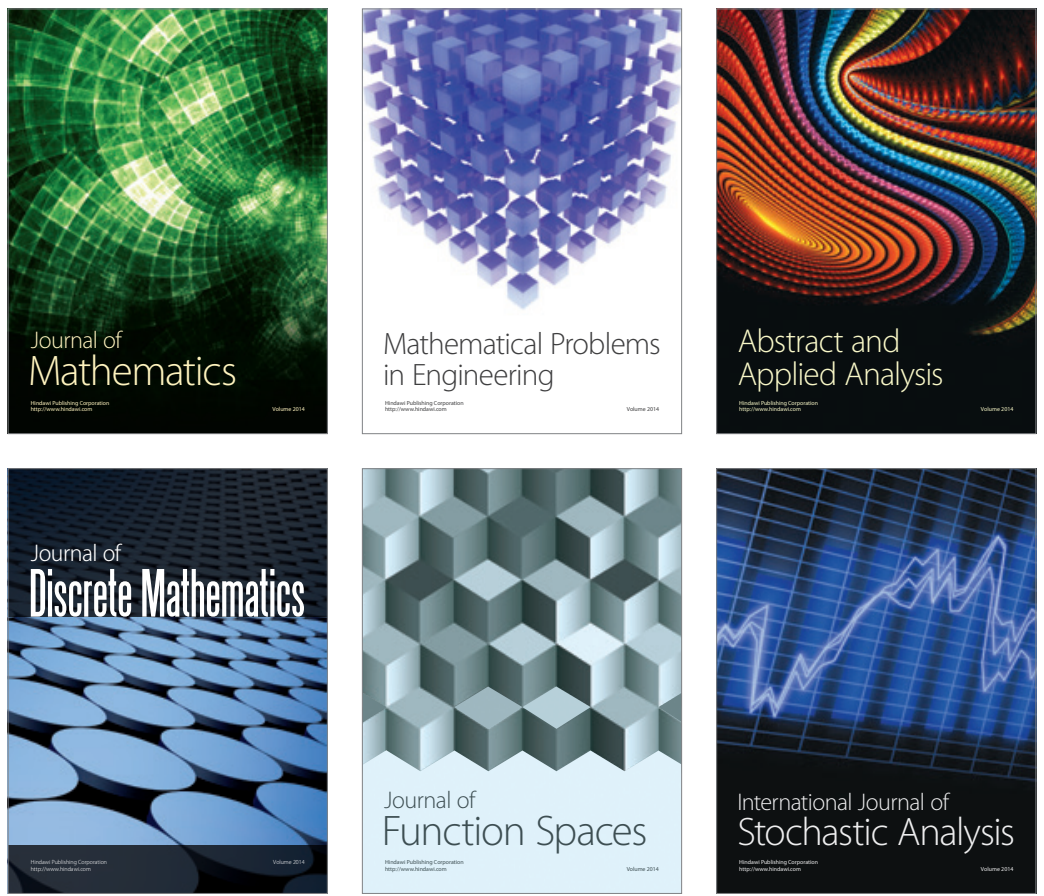

Journal of

Function Spaces

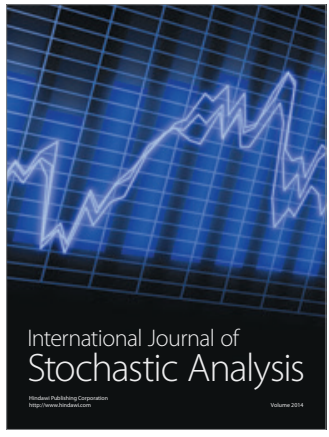

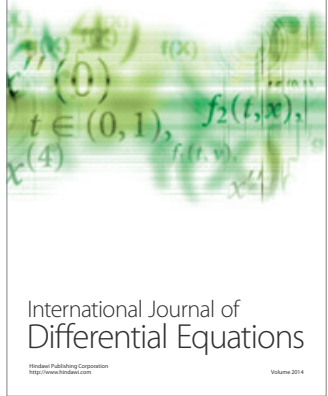
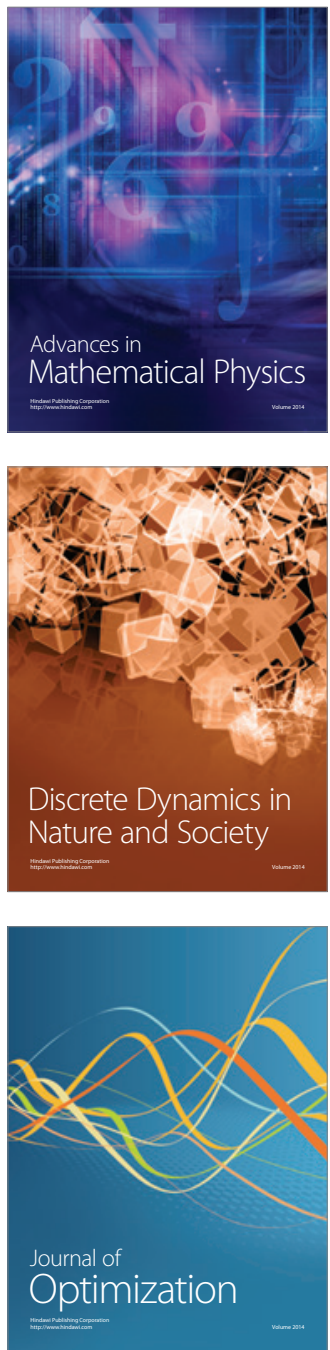